\title{
Numerical investigation of slip flow phenomenon on performance characteristics of gas foil journal bearing
}

\author{
Mohammad Autif Shahdhaar ${ }^{1}$ (D) Sandeep S. Yadawad ${ }^{1} \cdot$ Debanshu S. Khamari $^{1} \cdot$ Suraj K. Behera ${ }^{1}$
}

Received: 14 April 2020 / Accepted: 3 September 2020 / Published online: 11 September 2020

(c) Springer Nature Switzerland AG 2020

\begin{abstract}
Gas foil bearings (GFBs) are often employed in turbomachinery, particularly in high-speed turbochargers and turboexpanders. These bearings operate at very high speed and under very low clearance. On account of very low clearance, velocity slip can be observed at the gas-solid-interface. This paper investigates the effect of slip on various performance characteristics of the GFB. A model is put forth to predict the pressure and film thickness of a Gas Foil Journal Bearing (GFJB) used in helium-liquefaction turboexpander operating at $240 \mathrm{krpm}$. The present model addresses the slip at the gas-foil interface. Modified Reynolds equation, assuming first-order slip, is used along with the structural equation, which illustrates the compliant property of the foil. A numerical model is developed by finite difference approximation and solved by an iterative method. Various performance parameters are assessed for the no-slip and slip flow phenomenon in GFJB. The results are compared and a considerable difference is seen between the two models. The conventional Reynolds equation overestimates the load by approximately $8 \%$ at $240 \mathrm{krpm}$. The load-carrying capacity at different values of Knudsen number is also shown.
\end{abstract}

Keywords Gas foil bearings · Journal bearing · Turboexpander · Knudsen number · Slip flow

\section{List of symbols}

C Radial clearance ( $m$ )

$D \quad$ Kinetic diameter of the gas molecule $(\mathrm{m})$

E Young's modulus of the material of bump foil (N/ $\mathrm{m}^{2}$ )

GFB Gas foil bearing

GFJB Gas foil journal bearing

$h \quad$ Fluid film thickness ( $m$ )

$h_{b} \quad$ Height of bump (m)

$k_{b} \quad$ Boltzmann constant $\left(\mathrm{m}^{2} \mathrm{~kg} / \mathrm{s}^{2} \mathrm{~K}\right)$

Kn Knudsen number

$L \quad$ Length of the bearing $(\mathrm{m})$

$p \quad$ Pressure $\left(\mathrm{N} / \mathrm{m}^{2}\right)$

$p_{0} \quad$ Ambient pressure $\left(\mathrm{N} / \mathrm{m}^{2}\right)$

$R \quad$ Radius of the shaft (rotor) (m)

$R_{b} \quad$ Radius of bump (m)

$S \quad$ Pitch of the bump foil $(\mathrm{m})$ $t_{b} \quad$ Thickness of foil ( $\left.\mathrm{m}\right)$

$T \quad$ Temperature (K)

$U \quad$ Tangential velocity of the journal $(\mathrm{m} / \mathrm{s})$

$u_{\text {slip }} \quad$ Slip velocity at solid-gas interface $(\mathrm{m} / \mathrm{s})$

$\Lambda \quad$ Compressibility or bearing number

$\alpha \quad$ Compliant number

$\varepsilon \quad$ Eccentricity ratio

$\lambda \quad$ Mean free path of gas molecules $(\mathrm{m})$

$\mu \quad$ Dynamic viscosity $\left(\mathrm{N} \mathrm{s} / \mathrm{m}^{2}\right)$

$\mu_{0} \quad$ Dynamic viscosity of Helium gas at ambient temperature $\left(\mathrm{N}-\mathrm{s} / \mathrm{m}^{2}\right)$

$v \quad$ Poisson's ratio of material of bump foil

$\rho \quad$ Density of Helium gas $\left(\mathrm{kg} / \mathrm{m}^{3}\right)$

$\sigma \quad$ Tangential momentum accommodation coefficient

$\omega \quad$ Angular velocity (rad/s)

Mohammad Autif Shahdhaar, autifshahdhaar@gmail.com | ${ }^{1}$ Department of Mechanical Engineering, National Institute of Technology Rourkela, Rourkela 760098, India. 


\section{Introduction}

Turbomachines, especially turboexpanders, have surged to pre-eminence over the past few decades [1, 2]. Recent developments in turbomachinery have made high-speed machines, such as cryogenic turboexpanders, compact and capable of high-speed operation ranging from 10 $\mathrm{krpm}$ to over $200 \mathrm{krpm}$. Bearings play a pivotal role in such mechanical systems. Being a precision machine and operating at high speed without contamination, the selection of the bearing for turboexpander narrows down to gas bearings.

Gas bearing came into the picture when NASA put forth the concept of "frictionless bearing" or air bearing. The main drawback of gas bearing was its low stiffness and damping, thus limiting its use for small load-carrying applications. However, the evolving design of the gas foil bearings (GFBs) has improved the dynamic characteristics of the gas bearings, enhancing its scope of application. The GFBs are capable of operating at a speed over $500 \mathrm{krpm}[3,4]$. Gas foil journal bearings (GFJBs) and gas foil thrust bearings (GFTBs) are used to bear radial loads and axial loads, respectively, developed in the rotor of the turboexpander.

In 1994, Heshmat et al. effectuated ground-breaking enhancement in the design of foil bearings by performing a dynamic analysis, and achieved a load-carrying capacity of 6.735 bar at a rotational speed of $59.7 \mathrm{krpm}$ [5]. In 1983, Walowit studied the hydrodynamic behavior of gas foil bearing, where they used the Newton-Raphson method to solve the non-linear Reynolds equation [6]. In 1993, Peng and Carpino [7] used finite difference method (FDM) to calculate the stiffness and damping coefficients for a compliant bearing and extended the model to include the effects of friction on damping characteristics [8]. In 2000, Dellacorte and Valco derived an empirical formula to assess the load-carrying capacity [9]. Several experimental and theoretical investigations show that the foil gas bearing is more stable in comparison to the rigid gas bearing $[5,9]$. In 2004, Peng and Khonsari put forth a model to predict the elastohydrodynamic behavior of the GFB [10]. A series of investigations have been done to predict bearing performance due to variation in parameters like the clearance, journal speed, compliance, etc. and reported in the literature [5, $10,11]$. Rubio and San Andrés, in 2006, studied individual bump stiffness for its dependence on the bump structure and material, Coulomb friction, clearance and preload [12]. Lee et al. carried out a numerical and experimental investigation to assess the static and dynamic characteristics of the GFB by integrating the bending effect of top foil and the interaction between bump foil and top foil [13]. Owing to the substantial reliance of dynamic properties on the design and elastic properties of the bump foil [14], different configurations of foil, other than the conventional corrugated bump foil, have been proposed in the state-ofthe-art to meliorate the load-carrying capacity and stability of GFBs [15-18]. In Tkacz et al. numerically analyzed the dynamics of a GFJB, considering the relative motion and friction between the stationary elements of the sleeve [19]. Posterior to the numerical investigation, climacteric experimental works were carried out by Hou et al. [20], Li et al. [21] and Kayo and Liebich [22]. Hou et al. [20] carried out experimental analysis to study the behavior of GFB by replaced the aerostatic bearing with Generation I bump type GFB in a commercial cryogenic turboexpander. Li et al. [21] studied the effect of changing environmental pressure and rotor speed on the performance of the GFB. A significant increase in the load-carrying capacity of the GFB was observed at enhanced environmental pressure, which amplified exponentially with speed. Kayo and Liebich [22] experimentally reported linear static stiffness for GFB under low clearance while the dynamic stiffness increases with an increase in the load frequency.

Whilst many models for GFBs show decent consistency with the experimental data, the accuracy of the results can be enhanced, making the models more robust and versatile, by encompassing the behavior of the fluid under low and ultra-low clearance operations [23]. Generally, in the hydrodynamic analysis of gas bearings, the fluid is assumed to behave as a continuum. In some cases, the thickness of the fluid film is comparative to the mean free path of the gas; as such, the classic continuum assumption is not justified. In order to account for the microscopic discontinuities and predict the performance of the bearing accurately, the classic continuum model is modified. These modifications are expressed as velocity slip at the walls. Burgdorfer [24] pioneered the study of the behavior of fluid film under low and ultra-low clearance operations. A modified Reynolds equation was proposed, which included the slip flow condition at the solid-gas interface. An experimental investigation was carried out by $\mathrm{Hsia}$ and Domoto [25] to study the impact of molecular rarefaction encompassed the appraising of slider bearings in distinct gaseous media of varying mean free paths.

The present paper examines the impact of slip flow on the various operational characteristics of the GFJB. The flow analysis under the assorted ranges of Knudsen number is discussed. The continuum model is revamped by introducing first-order velocity slip at the solid-gas interface. The theoretical model is proposed by modifying the Reynolds equation, encompassing the slip flow boundary conditions. The FDM discretization concomitant with an iterative method is employed to compute the pressure and film thickness developed in the bearing. The influence of slip flow on various performance parameters is discussed. 
In addition to this, the results are compared with no-slip condition to assess the significance of slip flow in the analysis of very low clearance GFJBs.

\section{Theory}

Gas foil journal bearing comprises a bearing case lined with a pair of corrugated foil and a flat top foil. The corrugated bump foil tailors the stiffness and damping of the bearing while supporting the top foil. The top foil conceals the corrugated foil and is fastened to the bearing casing at one edge. The fluid film is formed between the rotating journal and the top foil. The pressure is generated, which carries the load of the rotating journal. The hydrodynamic pressure also results in deflection of the top foil due to the compliance of the corrugated foil. The configuration of the GFJB is shown in Fig. 1.
During the operation of the journal bearing, a fluid film is developed between the two tribo-surfaces. This thin film acts as the lubricant and imparts the requisite pressure to carry the load. In gas foil bearings, the thickness of the lubricating gas is minimal and reaches the order of few microns. The effects of the rarefaction at the wall have to be considered for modeling the comportment of the gas-bearing.

The Knudsen number for the bearing is given as

$K n=\frac{\lambda}{h_{\min }}$

where $\lambda$ is the mean free path of the gas and $h_{\min }$ represents the minimum film thickness [26]. The Knudsen number is vital in the selection of the boundary conditions in various fluid flows. Figure 2 depicts various flow regimes
Fig. 1 Schematic top sectional view of GFJB

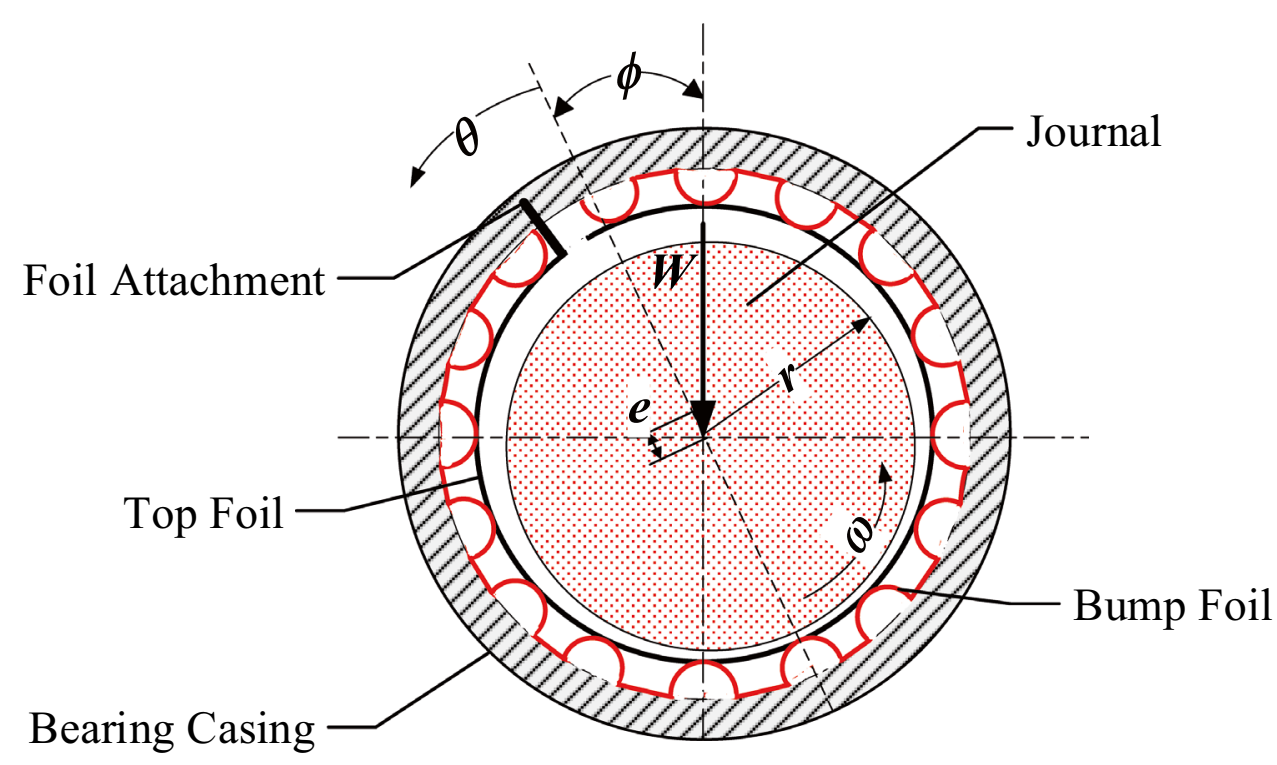

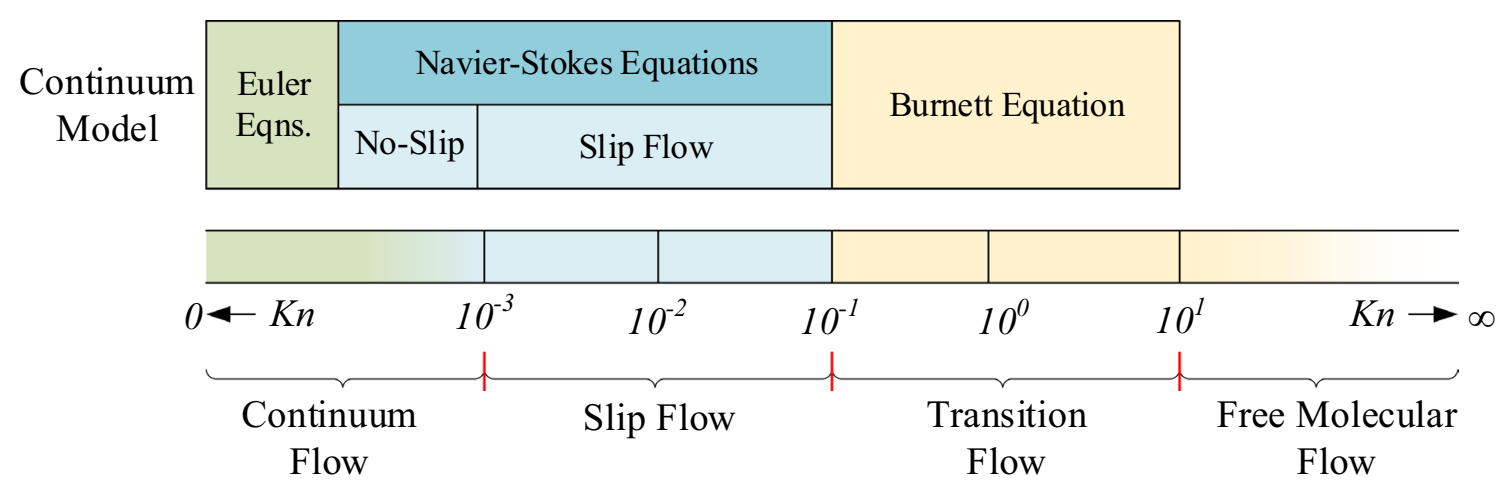

Fig. 2 Various regimes based on Knudsen number 
for the corresponding ranges of Knudsen number. Kinetic theory of gases gives the mean free path of the gas as [27].

$\lambda=\frac{k_{b} T}{\sqrt{2} \pi d^{2} p}$

where $k_{b}$ is the Boltzmann constant, and $d$ is the kinetic diameter of the molecule. The minimum film thickness, obtained by the Reynolds equation, and mean free path are used to compute the Knudsen number.

For Knudsen number lying between $10^{-3}$ to $10^{-1}$, the flow is continuous, and Navier-Stokes equations hold good. However, the no-slip condition is no longer applicable, and the velocity slip must be taken into consideration near the wall [28].
The magnitude of slip velocity is given by the first-order slip model or Maxwell's slip model for $K n<0.1$. The velocity of slip, neglecting higher-order terms, is given as [24]

$u_{\text {slip }}=\left.\frac{2-\sigma}{\sigma} \lambda \frac{\partial u}{\partial \eta}\right|_{\text {wall }}$

where $\sigma$ is the tangential momentum accommodation coefficient (TMAC) or reflection coefficient. For helium, the TMAC, $\sigma=0.93$ for $0.029<K n<0.47$ [29] (Fig. 3).

The incorporation of the velocity of slip and formulation of modified Reynolds equation is detailed in "Appendix 1". Figure 4 shows the coordinate system used in the present analysis. The modified Reynolds equation obtained for compressible fluid is written as

$\frac{\partial}{\partial x}\left[p h^{3} \frac{\partial p}{\partial x}\left\{1+6\left(\frac{2-\sigma}{\sigma}\right) K n\right\}\right]+\frac{\partial}{\partial z}\left[p h^{3} \frac{\partial p}{\partial z}\left\{1+\sigma\left(\frac{2-\sigma}{\sigma}\right) K n\right\}\right]=6 \mu \cup \frac{\partial}{\partial x}(p h)$

Fig. 3 Schematic diagram of slip flow at the solid-gas boundary
Fig. 4 Coordinate system used in the analysis
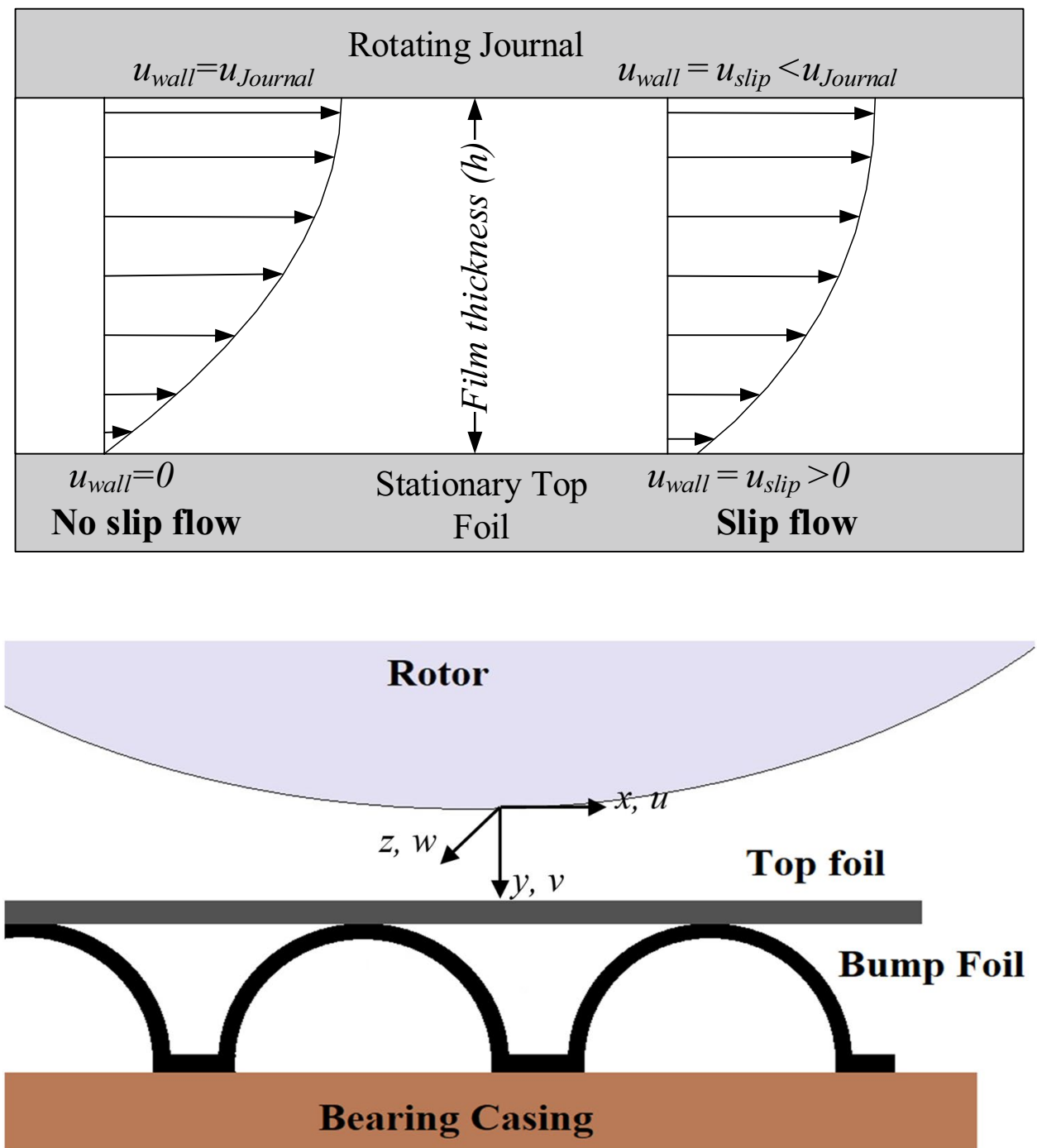
Dimensionless form of Eq. (1) is:

$\frac{\partial}{\partial \theta}\left[\bar{p} H \frac{\partial \bar{p}}{\partial \theta}\right]+\left(\frac{D}{L}\right)^{2} \frac{\partial}{\partial \bar{z}}\left[\bar{p} H \frac{\partial \bar{p}}{\partial \bar{z}}\right]=\Lambda \bar{\mu} \frac{\partial}{\partial \theta}(\bar{p} \bar{h})$

where $\Lambda$ is the bearing number, and

$$
\begin{aligned}
& \bar{z}=\frac{2 z}{L}, \bar{p}=\frac{p}{p_{0}}, \bar{h}=\frac{h}{C}, \theta=\frac{x}{R}, \bar{\mu}=\frac{\mu}{\mu_{0}} \\
& H=\bar{h}^{3}\left\{1+6\left(\frac{2-\sigma}{\sigma}\right) K n\right\} \text { and } \Lambda=\frac{6 \omega \mu_{0}}{p_{0}}\left(\frac{R}{C}\right)^{2}
\end{aligned}
$$

\subsection{Boundary conditions}

The bearing is subjected to ambient pressure on both ends and is symmetric along mid-plane along the bearing length. Hence, the non- dimensional pressure boundary conditions for the Reynolds equation are given as

$$
\begin{aligned}
\bar{p}(\theta=0) & =\bar{p}(\theta=2 \pi)=1 \\
\bar{p} & =1 \text { at } \bar{z}= \pm 1 \\
\frac{\partial \bar{p}}{\partial \bar{z}} & =0 \text { at }(\bar{z}=0)
\end{aligned}
$$

In GFJB, the gas film thickness $(\bar{h})$ depending on two parameters, the eccentricity of the journal and other deals with compliance property of foil. The normalized film thickness is:

$\bar{h}=1+\varepsilon \cos \theta+\alpha(\bar{p}-1)$

where $a$ is the non-dimensional compliance number given as [6] (Fig. 5). $\alpha=\frac{2 p_{0} s}{C E}\left(\frac{1}{t_{b}}\right)^{3}\left(1-v^{2}\right)$

The pressure and film thickness are calculated by coupling the Modified Reynolds equation and the structural equation for the film thickness. The calculated pressure is used to calculate the load-carrying capacity by [30]

$$
\begin{aligned}
& \bar{W}_{x}=\int_{-1}^{1} \int_{0}^{2 \pi}(\bar{p}-1) \cos \theta d \theta d z \\
& \bar{W}_{z}=\int_{-1}^{1} \int_{0}^{2 \pi}(\bar{p}-1) \sin \theta d \theta d z
\end{aligned}
$$

$\bar{W}=\sqrt{{\overline{W_{x}}}^{2}+\bar{W}_{z}^{2}}, \phi=\tan ^{-1}\left(-\frac{\bar{W}_{z}}{\bar{W}_{x}}\right)$

where $\bar{W}_{x}, \bar{W}_{z}$ and $\bar{W}$ represent non- dimensional loads along the line of centers, perpendicular to line of centers and the net dimensionless load-carrying capacity, respectively, $W=\bar{W} p_{0} R L$ is the load capacity in (N). $\phi$ is the attitude angle, defined as the angle between the line of centers and the line of action of the load.

\section{Numerical methodology}

The modified Reynolds equation is a non-linear differential equation for pressure and is solved by a numerical iterative method. The structural equation is coupled with the modified Reynolds equation to calculate pressure and film thickness. The modified Reynolds equation is rearranged and yields

$\frac{\partial^{2} \bar{p}}{\partial \theta^{2}}+\left(\frac{D}{L}\right)^{2} \frac{\partial^{2} \bar{p}}{\partial \bar{z}^{2}}=-\frac{1}{\bar{p}}\left[\left\{\left(\frac{\partial \bar{p}}{\partial \theta}\right)^{2}+\left(\frac{D}{L}\right)^{2}\left(\frac{\partial \bar{p}}{\partial \bar{z}}\right)^{2}\right\}\right]-\frac{1}{H} \frac{\partial H}{\partial \theta} \frac{\partial \bar{p}}{\partial \theta}+\Lambda \bar{\mu} \frac{\partial}{\partial \theta}(\bar{p} \bar{h})$

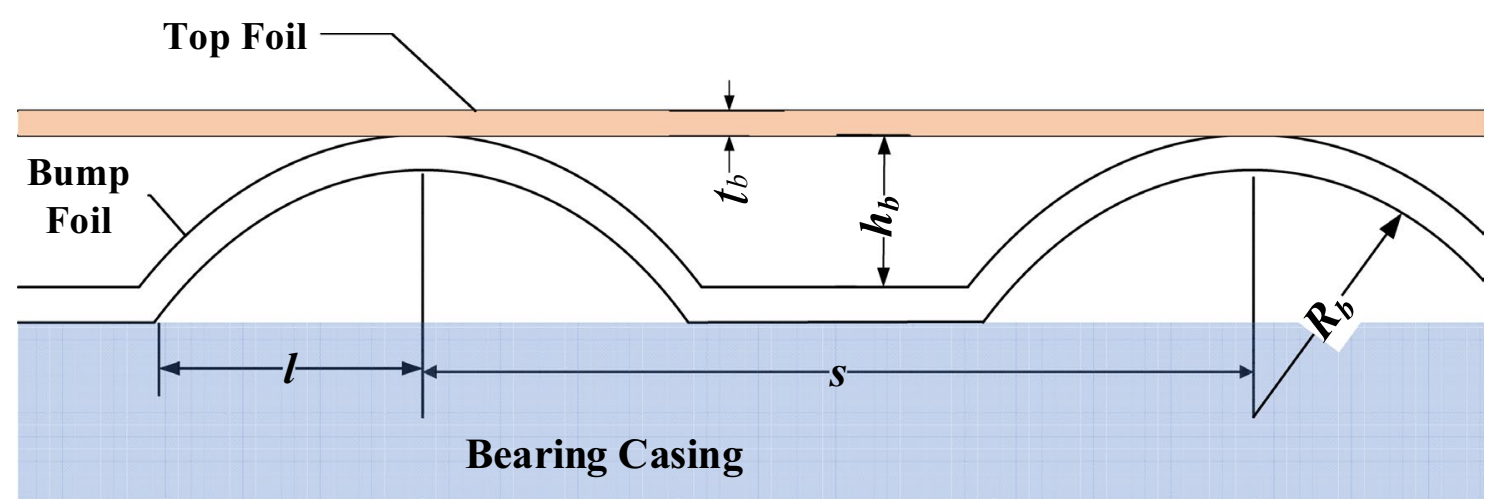

Fig. 5 Geometry of Bump Foil 
Finite difference methodology is used to convert the differential Eq. (6) to a difference equation by second-order central difference approximation. "Appendix 2 " illustrates the discretized form of the aforementioned equation.

The domain is divided into 100 divisions along the circumferential direction and 30 divisions along the axial direction. The pressure variation across the film thickness is insubstantial. The solution begins by initializing the pressure at all nodes as ambient pressure and calculating the film thickness for that pressure. The RHS of equation (ix) is evaluated and then solved for new value of pressure. The iterative method is applied at all the nodes and pressure updated. The iteration stops when the convergence criterion is satisfied. Convergence is attained when the difference between successive iterations falls below the desired tolerance. The simplified procedure for the analysis is shown in the flow chart in Fig. 6.

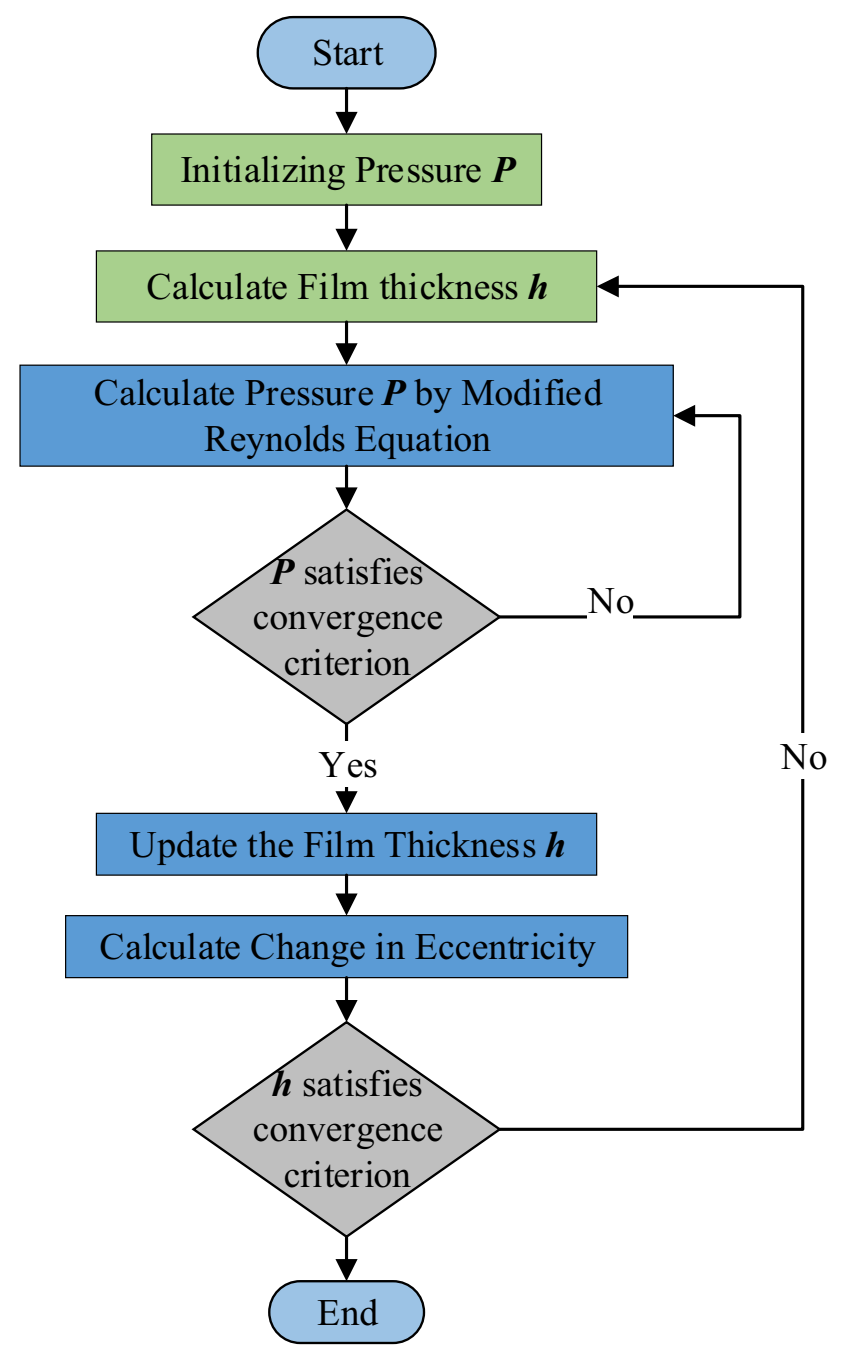

Fig. 6 Flow chart for the Solution Procedure
For the present model, the pressure convergence is achieved when the relative error is under $0.00001 \%$. The film thickness and eccentricity ratio are updated based on the updated pressure. The deflection of the foil does not vary in the axial direction, $z$. The average pressure along the $z$-direction is considered to calculate the deflection due to compliance.

$\bar{h}_{j}=1+(\varepsilon \cos \theta)_{j}+\alpha\left(\operatorname{mean}\left(\bar{p}_{i}\right)-1\right)_{j}$

The film thickness is updated based on the successive overrelaxation (SOR) scheme. The eccentricity ratio is adjusted based on the maximum change in the film thickness, as shown below:

$$
\begin{aligned}
\Delta \varepsilon & =\max \left(\alpha\left(\operatorname{mean}\left(\bar{p}_{i}\right)-1\right)\right) \\
(\varepsilon)^{n+1} & =(\varepsilon+\Delta \varepsilon)^{n}
\end{aligned}
$$

It is clear from Eq. (7) that the eccentricity ratio for the GFJB can be higher than unity resulting from the compliance of the foil. The updated film thickness and eccentricity ratio are again used to calculate pressure. The convergence criterion for the film thickness is based on the percentage error between two successive iterations. The solution is converged when the relative error is less than $0.0001 \%$.

Table 1 Data for the bearing

\begin{tabular}{ll}
\hline Parameter & Value \\
\hline Radius of the shaft $(\mathrm{R})$ & $8 \mathrm{~mm}$ \\
Length of bearing $(\mathrm{L})$ & $16 \mathrm{~mm}$ \\
Radial clearance $(\mathrm{C})$ & $25 \mu \mathrm{m}$ \\
Bump foil thickness $\left(\mathrm{t}_{\mathrm{b}}\right)$ & $0.1 \mathrm{~mm}$ \\
Pitch of bump $(\mathrm{s})$ & $4.2 \mathrm{~mm}$ \\
Half bump length $(\mathrm{l})$ & $1.32 \mathrm{~mm}$ \\
Young's modulus $(\mathrm{E})$ & $200 \mathrm{GPa}$ \\
Poisson's ratio $(v)$ & 0.29 \\
Speed of the shaft $(\mathrm{N})$ & $240 \mathrm{krpm}$ \\
Eccentricity ratio $(\varepsilon)$ & 0.8 \\
Height of the bump $\left(\mathrm{h}_{\mathrm{b}}\right)$ & $0.6 \mathrm{~mm}$ \\
Radius of the bump $\left(\mathrm{R}_{\mathrm{b}}\right)$ & $1.75 \mathrm{~mm}$ \\
\hline
\end{tabular}

Table 2 Data for the Lubricant $(\mathrm{He})$

\begin{tabular}{ll}
\hline Parameter & Value \\
\hline Viscosity $\left(\mu_{0}\right)$ & $18.7 \mathrm{e}-6$ Pa s \\
Density $(\rho)$ & $0.178 \mathrm{~kg} / \mathrm{m}^{3}$ \\
Kinetic diameter of atom $/$ molecule $(\mathrm{d})$ & $260 \mathrm{pm}$ \\
\hline
\end{tabular}


Fig. 7 Validation of present model with Peng and Khonsari [10]

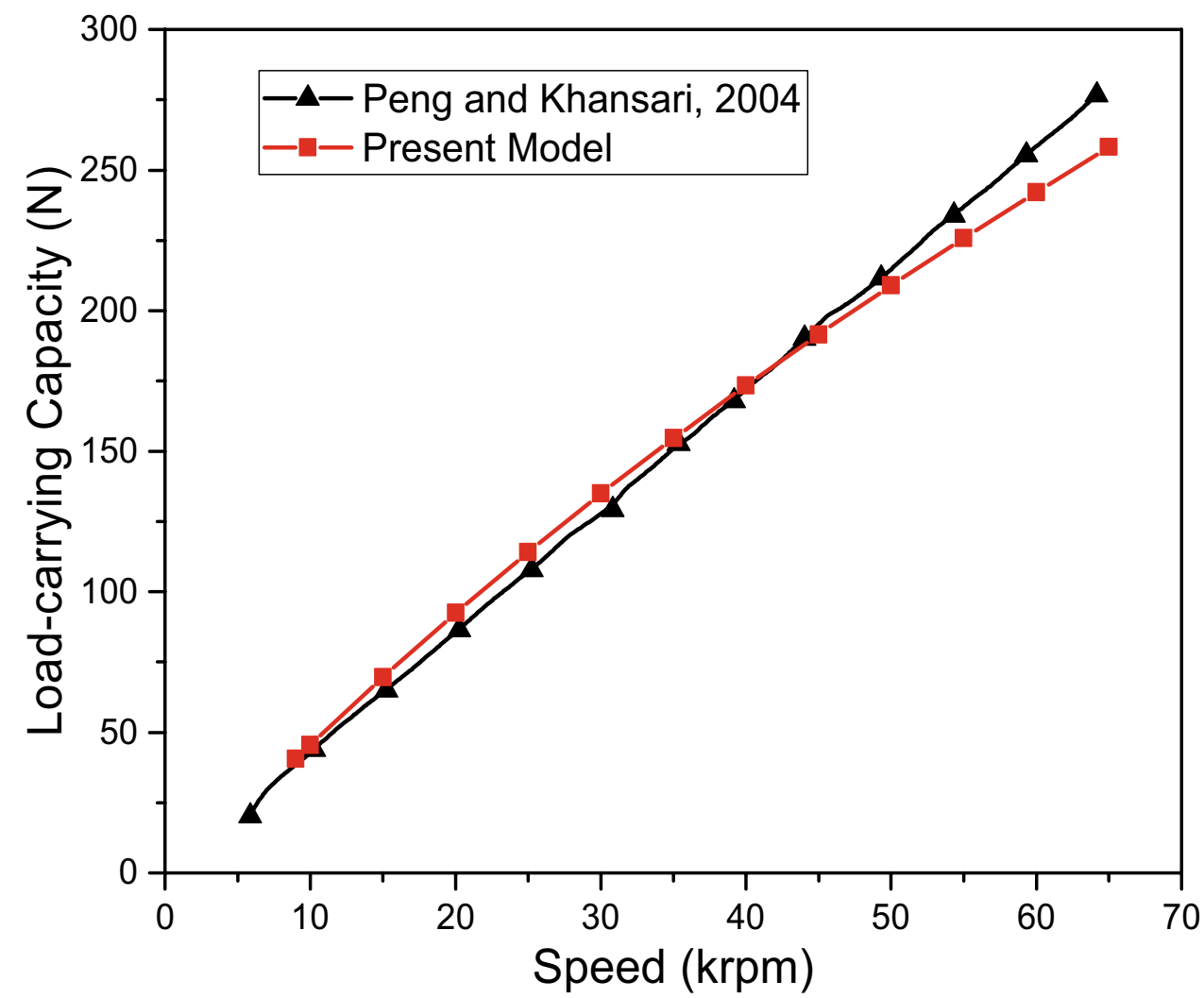

\section{Results and discussion}

The bearing parameters of the GFJB are given in Table 1, and the properties of the lubricant are shown in Table 2.

\subsection{Validation and grid independence}

Figure 7 shows the comparison of the load-carrying capacities of the present model and Peng and Khonsari [10]. It can be observed that the load predicted through the present model is in close correspondence with the data from the open literature. The deviation between the two curves is due to the assumption of some missing parameters that were not explicitly mentioned in the literature [10]. The grid size is optimized by carrying out a grid independence test, as depicted in Fig. 8. A grid size of 100 divisions along the circumferential direction is considered as the difference between the successive grid sizes is less than $0.05 \%$. Thus, the present analysis is carried out by considering 100 divisions and 30 divisions along the circumferential and axial direction, respectively.

\subsection{Pressure distribution}

In this section, the effect of slip flow on the mid-plane pressure profile for variation in the bearing parameters is discussed. Figures 9, 10 and 11 shows the mid-plane pressure profile for variation of rotor speed, clearance and eccentricity ratio of the bearing. The pressure developed in the bearing is lower when slip is taken into account. The difference between the corresponding pressure profiles of slip and no-slip flow is more prominent with an increment in speed and eccentricity ratio. This trend is also observed when the clearance between the two surfaces decreases. The normalized peak pressure at the midplane at $50 \mathrm{krpm}$ for bearing considering no-slip flow and slip flow is calculated as 2.11 and 2.016, respectively. For the journal speed of $240 \mathrm{krpm}$, the normalized peak pressure for bearing considering no-slip flow is 4.211 and 3.977 under slip flow. The no-slip assumption overestimates the peak hydrodynamic pressure by $5.56 \%$ at $240 \mathrm{krpm}$. As the velocity gradient increases, the velocity of slip increases, which in turn decreases the wedging action of the lubricant, thus, lowering the pressure generation. At low speeds $(<50 \mathrm{krpm})$, this difference is not prominent and can be neglected. However, at higher operational speeds and low film thickness, the effects of slip are noteworthy and have to considered to model the bearing accurately.

\subsection{Load-carrying capacity}

Load-carrying capacity is the maximum load the bearing can support while maintaining a fluid film between the journal and the top foil. The load-carrying capacity 
Fig. 8 Grid independence test

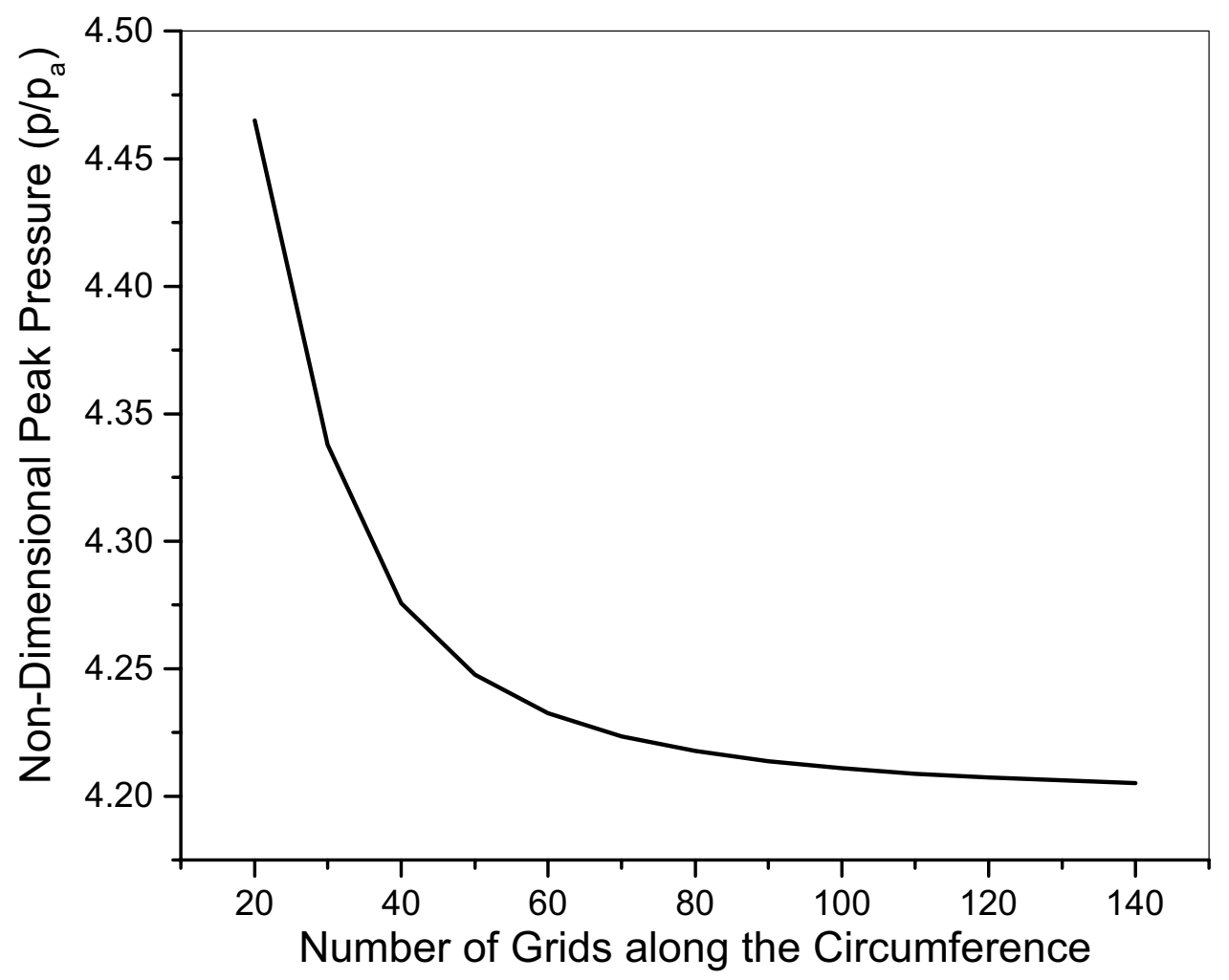

Fig. 9 Mid-plane pressure profile for No-Slip and Slip flow for various rotor speeds

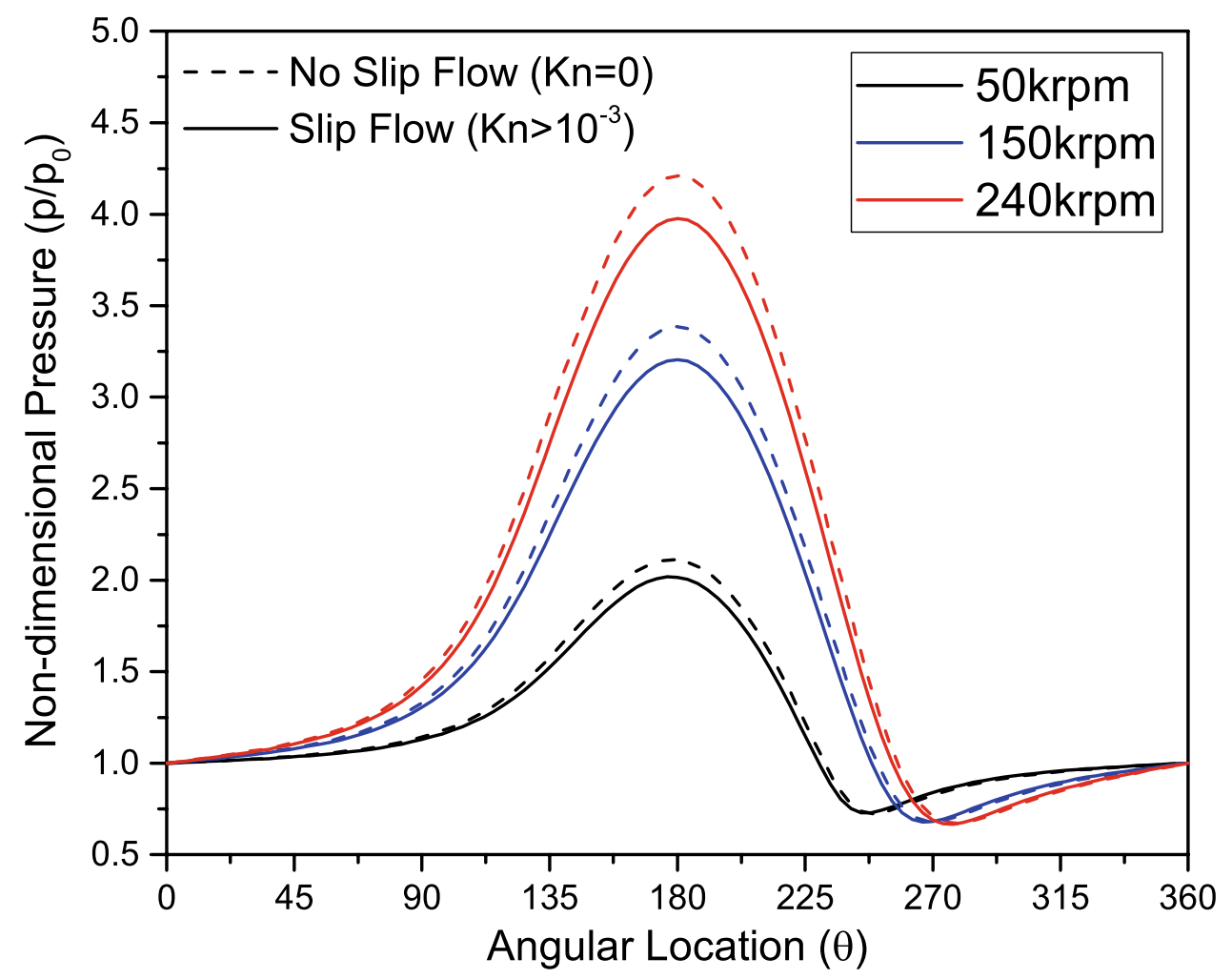

of the foil bearing is higher than the rigid bearing, as is noted from Fig. 12, because of the improved stiffness of the GFB. For the foil bearing, the pressure is distributed over a larger area compared to the rigid bearing, which is responsible for its increased load-carrying capacity [10]. For the operating speed of $240 \mathrm{krpm}$, the load-carrying 
Fig. 10 Variation of pressure at mid-plane with change in Radial Clearance

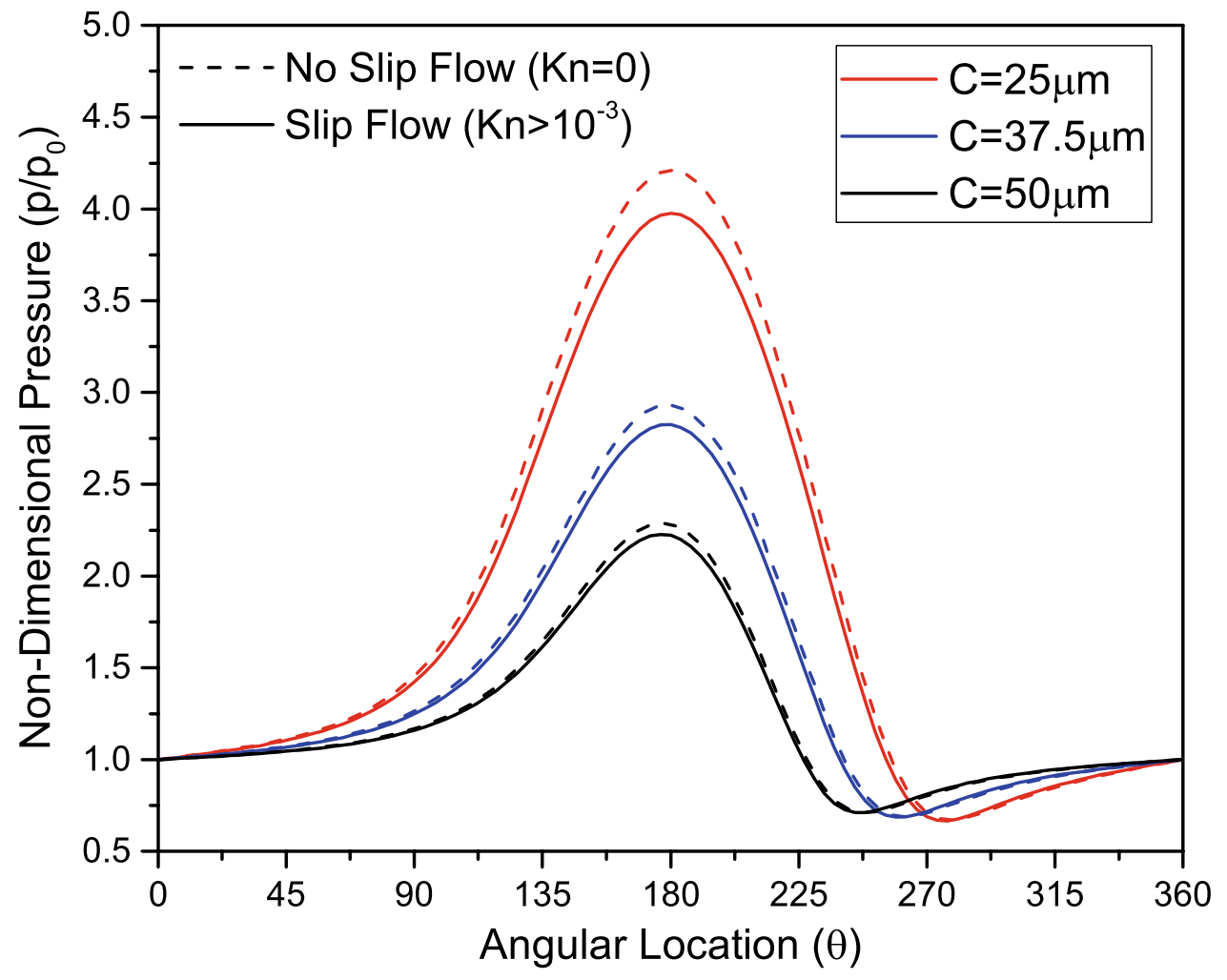

Fig. 11 Mid-plane pressure profile for no-slip and slip flow for various eccentricity ratios

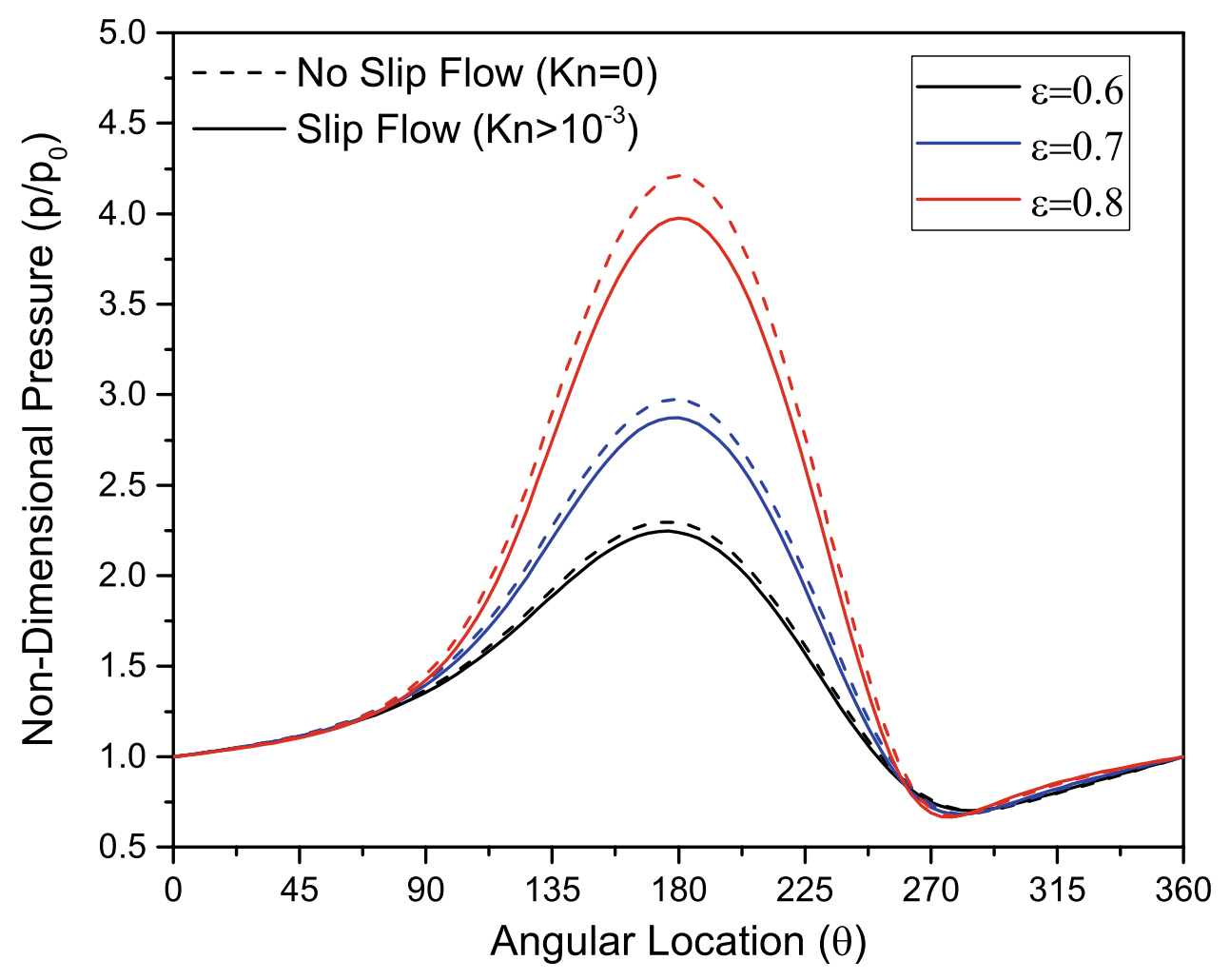


Fig. 12 Load-carrying capacity for no-slip and slip flow at different rotor speeds

Fig. 13 Load-carrying capacity for no-slip and slip flow with change in Radial Clearance
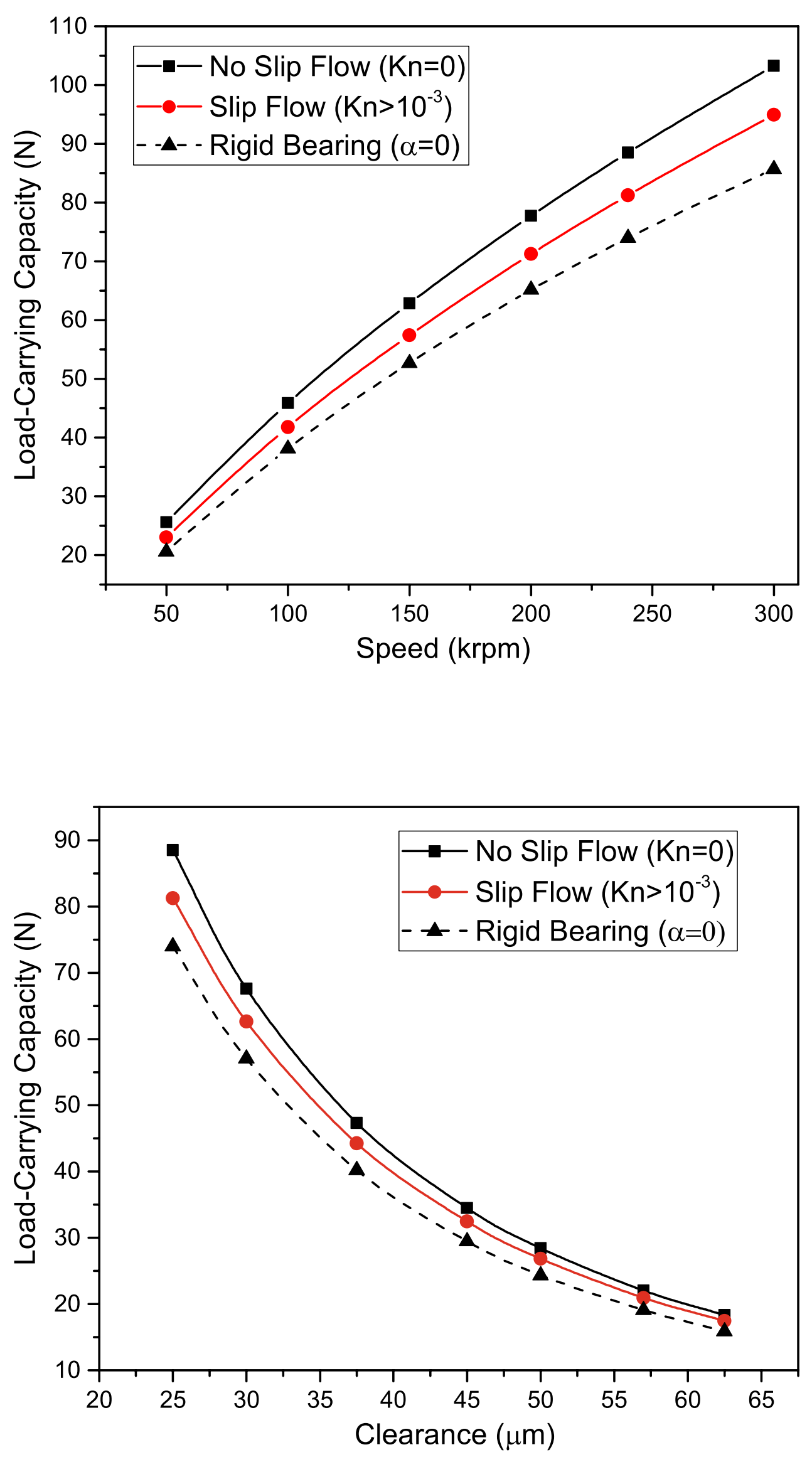
Fig. 14 Load-carrying capacity for no-slip and slip flow at different Eccentricity Ratios

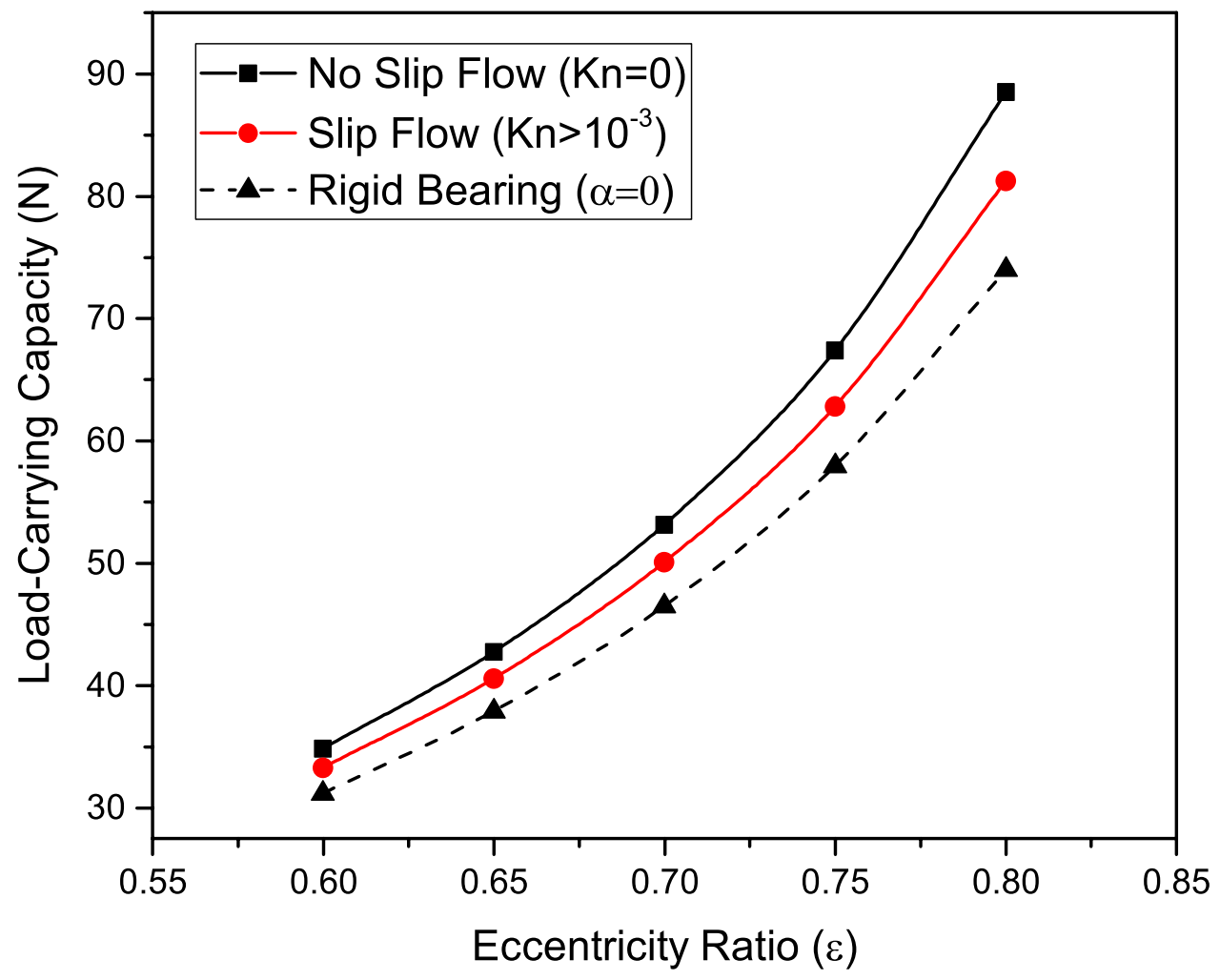

capacity attained by the foil bearing is $88.497 \mathrm{~N}$ compared to $73.995 \mathrm{~N}$ for that of the rigid bearing. The difference in the load-carrying capacity of the GFB and rigid bearing is more prominent as the rotor speed increases.

Figures 12, 13 and 14 shows the variance of load-carrying capacity with rotor speed, clearance, and the eccentricity ratio, respectively. A comparison is drawn between the load-carrying capacity of the compliant bearing, with and without considering the slip flow at the fluid-solid interface in the bearing. It is seen that the no-slip model tends to overestimate the load-carrying capacity of the bearing. The onset of slip near the interface results in lower the flow rate of gas (Helium) between the journal and the top foil. This attributes to the decrease in the wedging action and thus lower load-carrying capacity. Note that for monoatomic gas, such as helium, taking account of the slip velocities at the fluid-solid interface would produce more relatable results to the experimental analysis [25].

This can be attributed to the fact that the slip flow model is based on the ideal gas assumption. The effect of slip is magnified as the distance between the journal and the top foil decreases, as can be seen in Figs. 13 and 14. As the gap between the journal and the foil decrease, the load-carrying capacity does increase, but there is an increase in the slip velocity as well. Thus, the dissimilitude between the no-slip and the slip model increases as the two tribo-surfaces come nearer. The same phenomenon is observed as the journal speed increases, as depicted in Fig. 12.

The load-carrying capacity achieved at $50 \mathrm{krpm}$ for noslip flow and slip flow is $25.59 \mathrm{~N}$ and $22.99 \mathrm{~N}$, respectively, while at $240 \mathrm{krpm}$, the corresponding values are $88.497 \mathrm{~N}$ and $81.233 \mathrm{~N}$. This can be attributed to the increase in the velocity gradient and hence increase in slip velocity.

\subsection{Film thickness and eccentricity ratio}

A fluid film is formed between the journal and the top foil due to the relative motion, which drags the fluid through the converging region resulting in the generation of hydrodynamic pressure. The fluid film thickness varies with the design parameters and the compliance of the foil, as seen in Fig. 16. It is essential to note in Fig. 15 that the minimum film thickness remains unchanged with the change in the speed. In Figs. 15 and 16, it is intriguing to observe that the film thickness remains unaffected by the phenomenon of slip. However, as explained above, the eccentricity ratio changes in the complaint bearing and is greater than unity. In case of bearing operating at $240 \mathrm{krpm}$, the minimum film thickness for both slip and no-slip model converges to $5 \mu \mathrm{m}$.

However, the operating eccentricity ratio converges to 1.68 and 1.609 , respectively, for the no-slip model and slip flow model. The eccentricity ratio is lesser for the slip model due to less hydrodynamic pressure generation. 
Fig. 15 Mid-plane film thickness for no-slip and slip flow for various rotor speeds

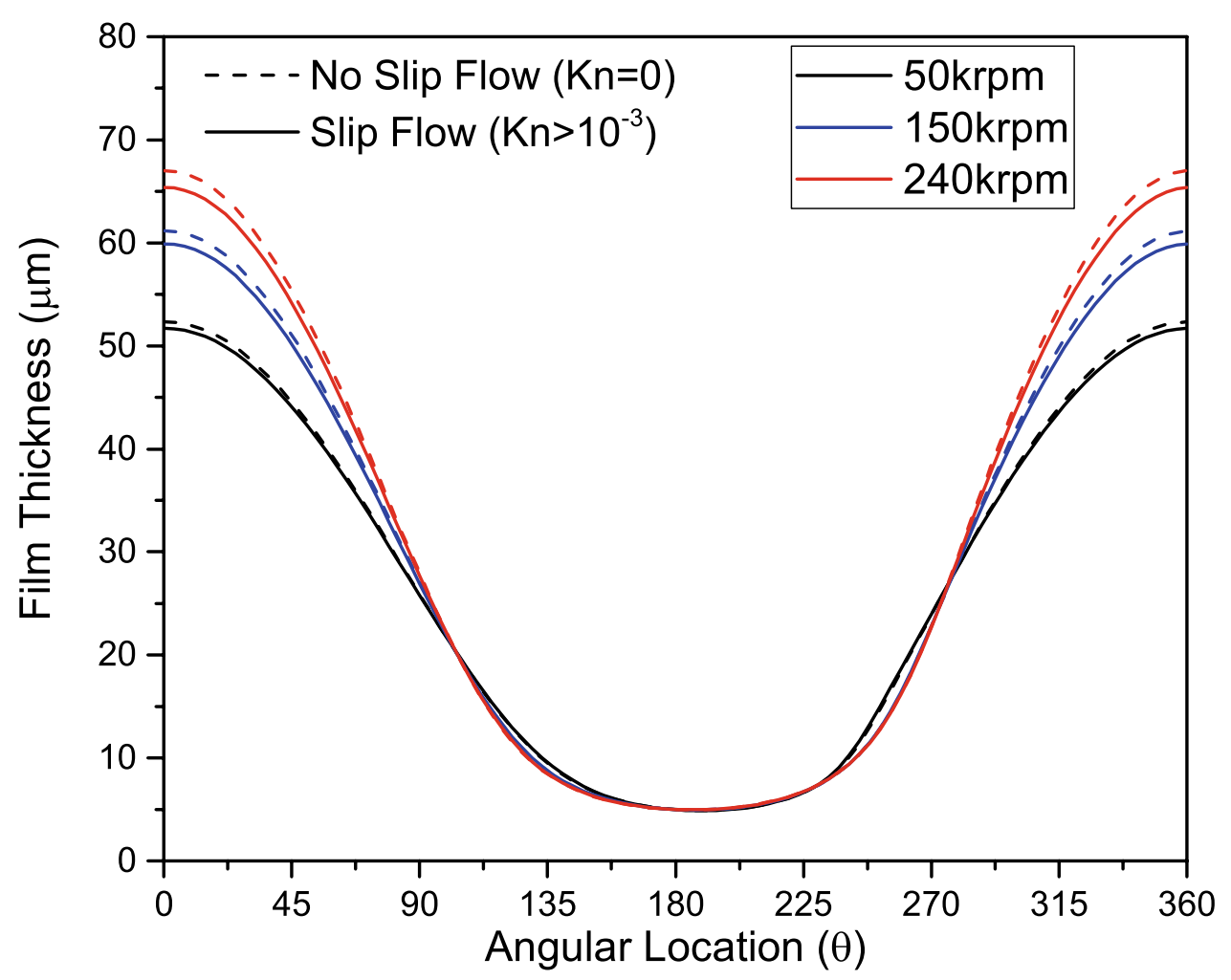

Fig. 16 Mid-plane fluid film thickness for no-slip and slip flow at different eccentricity ratios

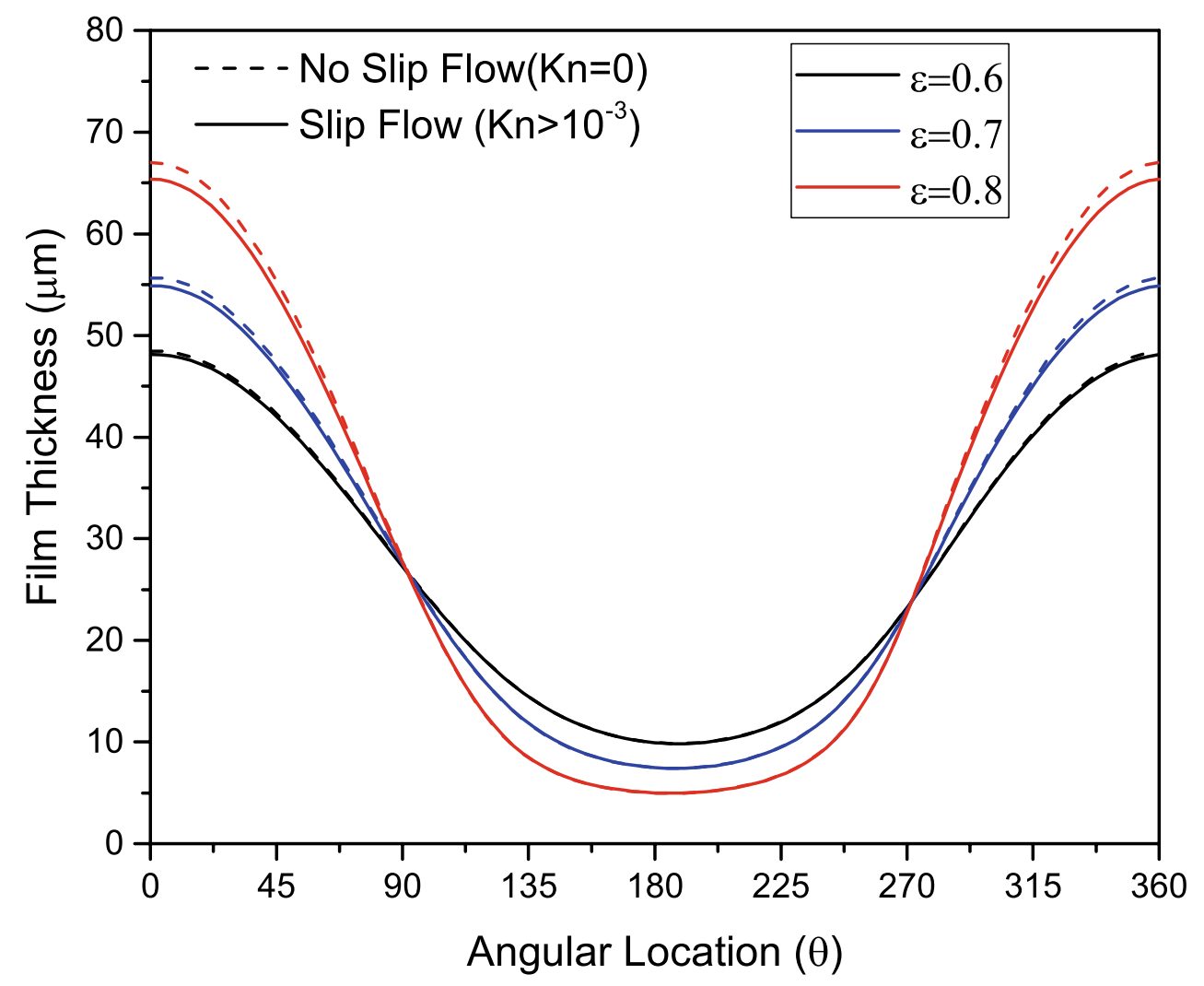


In the case of GFJBs, the foil deflects under the effect of the hydrodynamic pressure increasing the film thickness. The journal under load moves towards the foil, maintaining the minimum film thickness, which increases the eccentricity ratio.

This phenomenon results in deforming the foil into a dumbbell curve shape around the region of minimum film thickness. Thus, the convergent region is extended over a more significant angular extent around the circumference of the journal. As a result, the journal is subjected to more uniform pressure is around its circumference. This is one of the factors in foil bearings that improve operational stability at high operating speeds [5]. As discussed above, the eccentricity ratio of the bearing is lower under slip flow. This tends to decrease this "lobbing effect" of the foil around the journal. This can be reflected as a minor decrease in the stability of the bearing.

\subsection{Attitude angle}

The attitude angle is a significant parameter for assessing the stability of the bearing. Generally, a smaller attitude angle for a bearing implies better stability. Figures 17 and 18 shows the attitude angle of the rigid bearing is higher compared to the foil bearing. Note that a smaller attitude angle for foil bearing signifies that the journal will remain in a steady position and have fewer fluctuations. Thus, the foil bearing has improved stability over the rigid bearing.
It is interesting to observe that slip flow does not influence the stability of the bearing to a significant extent. The foil bearing still has a significantly small attitude angle as compared to the rigid bearing even when slip is taken into account. In Figs. 17 and 19, it can be seen that the difference between the attitude angle of the foil and rigid bearing remains almost constant as the speed and the eccentricity increases. It should be noted that the journal moves in parabolic static equilibrium states while the attitude angle decreases linearly with an increase in the eccentricity ratio [31]. The combined effect of the low attitude angle and extended convergent region of the film at high speed enhances the dynamic stability, which is essential from the whirl instability standpoint.

\subsection{Knudsen number}

Knudsen number is an important dimensionless number which is directly related to the magnitude of the slip velocity. Figure 20 shows the load-carrying capacity of the rigid bearing and the GFB varying with Knudsen number. Both bearings are assumed to have the same dimensions and operate under the same conditions. The load-carrying capacity of both rigid and foil bearing decreases as the Knudsen number increases. As the Knudsen number increases from $K n=0$ to $K n=0.05$ for the GFJB, the load-carrying capacity at $240 \mathrm{krpm}$ decreases by $17.61 \mathrm{~N}(19.6 \%)$ and $10.99 \mathrm{~N}(20.92 \%)$ at $120 \mathrm{krpm}$. The phenomenon of
Fig. 17 Attitude angle at various rotor speeds

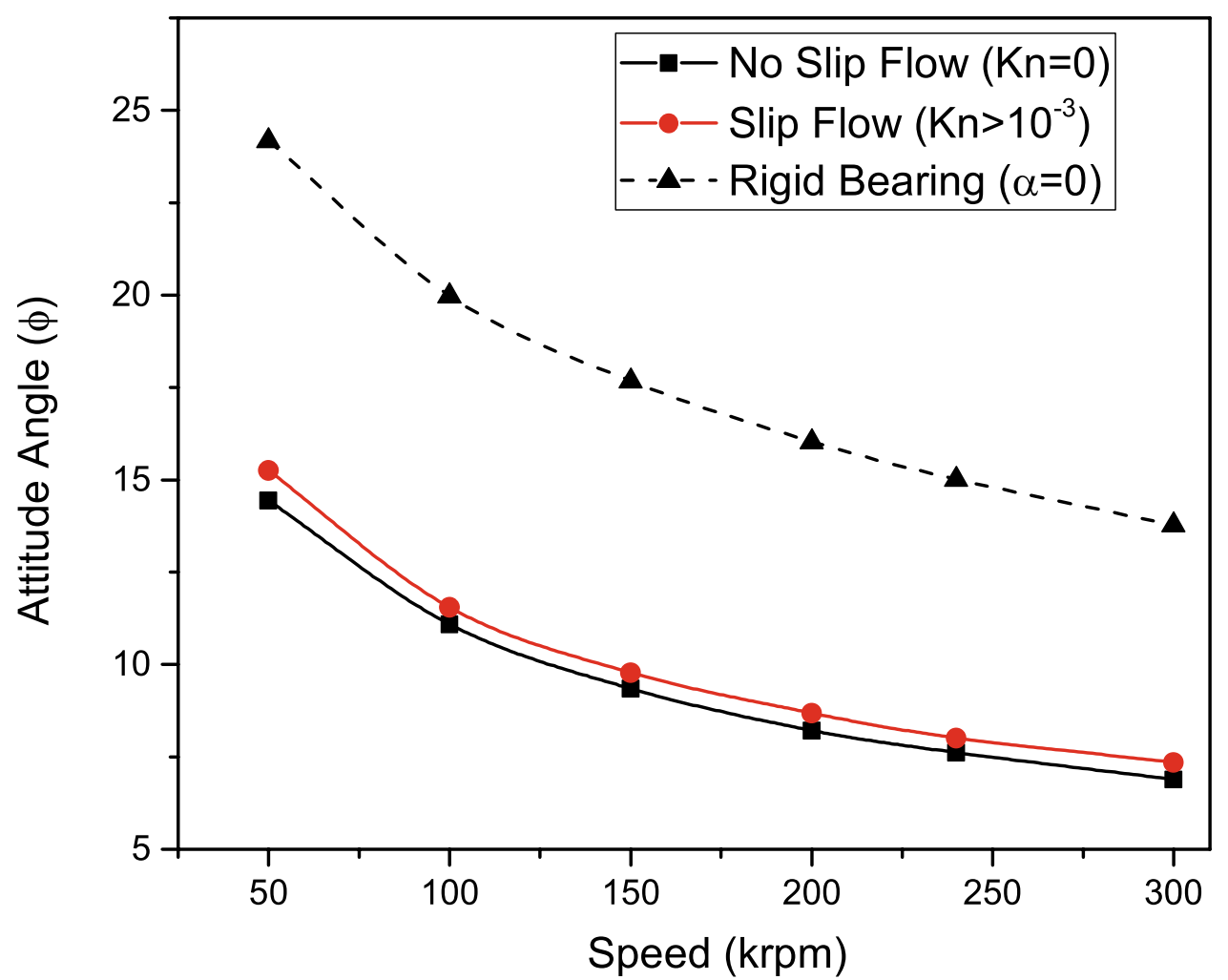


Fig. 18 Attitude angle at different values of radial clearance

Fig. 19 Variation of attitude angle with eccentricity ratio
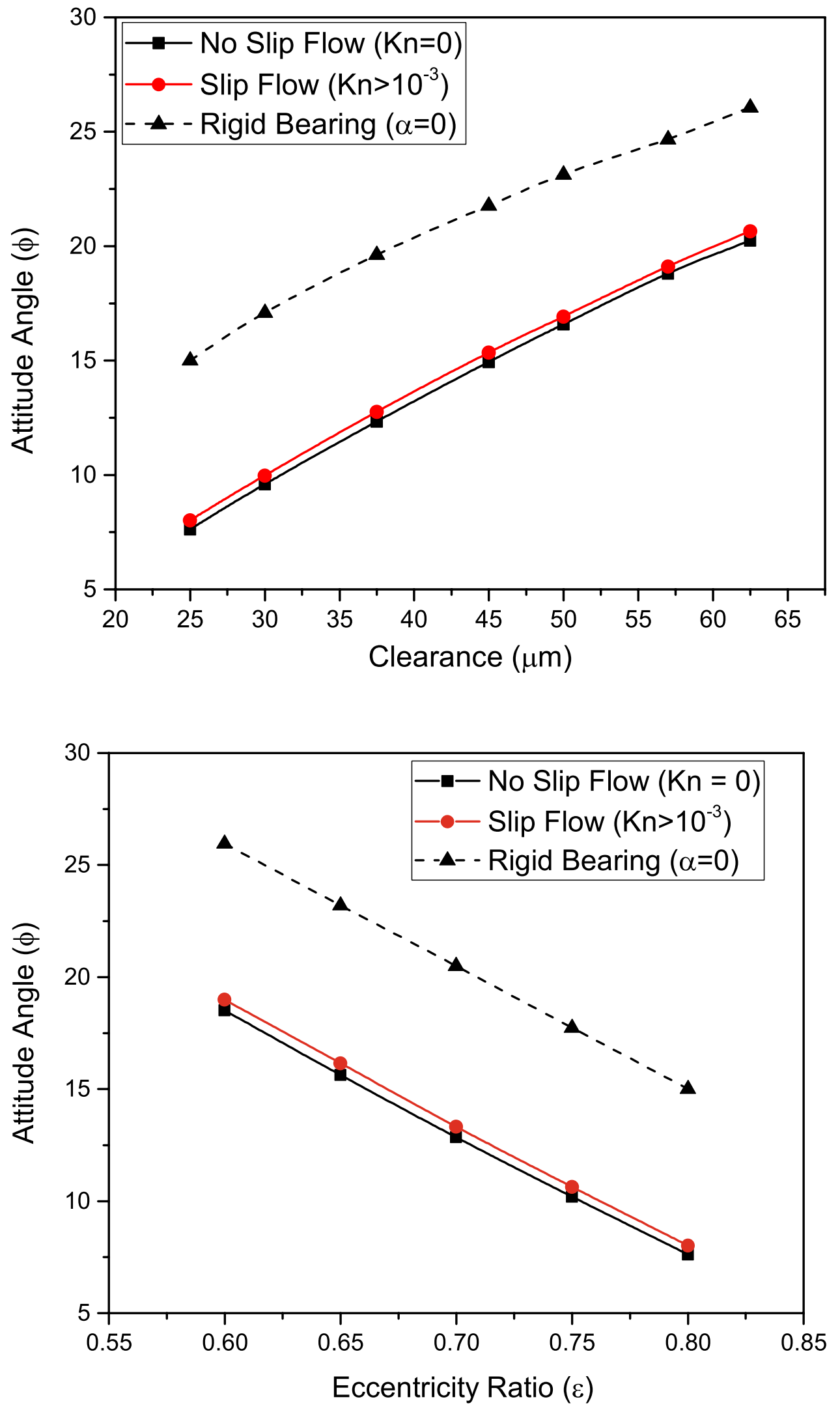
Fig. 20 Load-carrying capacity at various values of Knudsen number

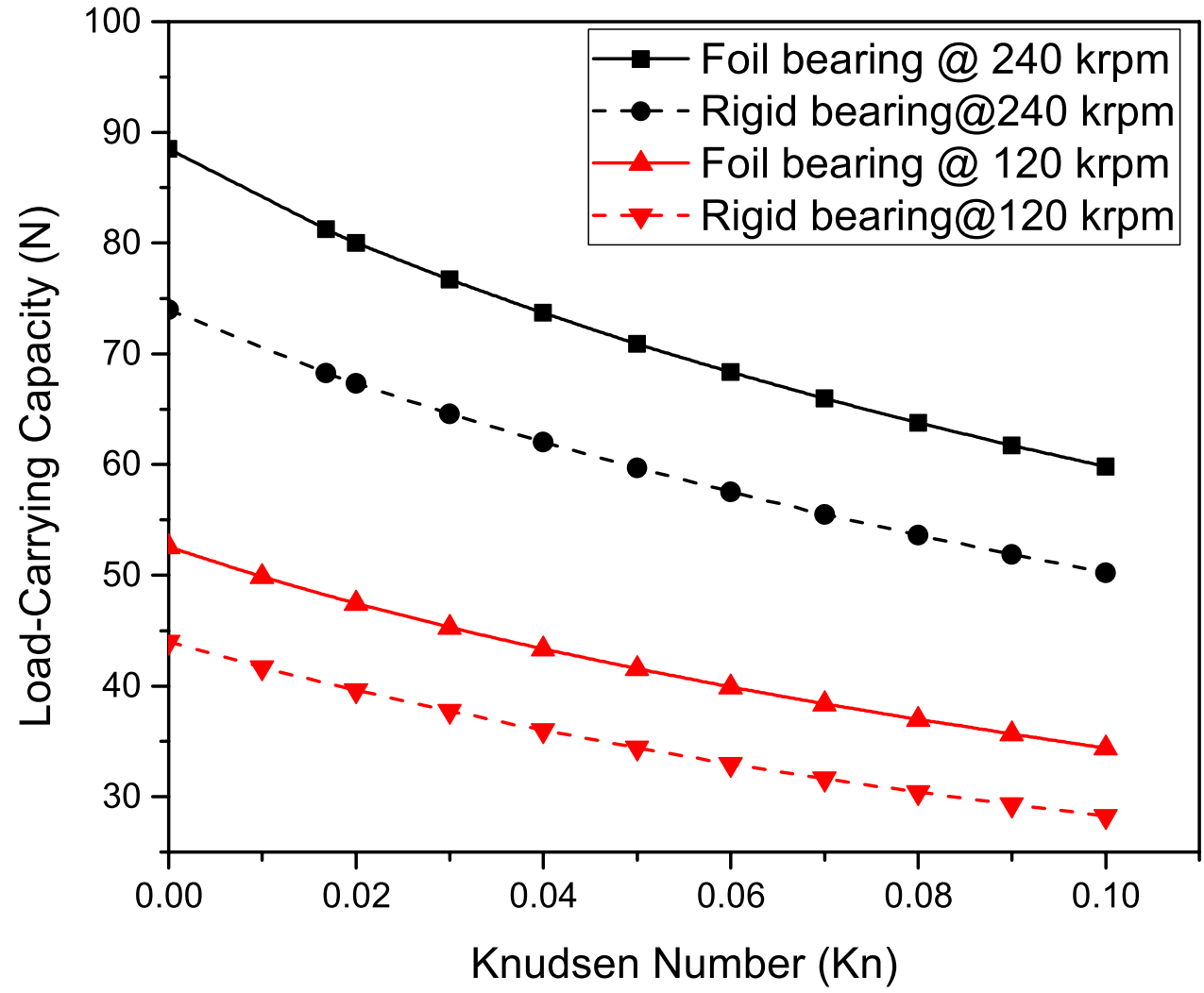

Table 3 Knudsen number for various lubricating gases at NTP

\begin{tabular}{lllll}
\hline Lubricating gas & \multicolumn{3}{l}{ Knudsen number } \\
\cline { 2 - 5 } & At $h_{\min }=50 \mu \mathrm{m}$ & At $h_{\min }=25 \mu \mathrm{m}$ & At $h_{\min }=10 \mu \mathrm{m}$ & At $h_{\min }=5 \mu \mathrm{m}$ \\
\hline Helium & 0.002294 & 0.004587 & 0.011468 & 0.022936 \\
Nitrogen & 0.001871 & 0.003742 & 0.009355 & 0.01871 \\
Air & 0.00136 & 0.00272 & 0.0068 & 0.0136 \\
Argon & 0.00126 & 0.00252 & 0.0063 & 0.0126 \\
\hline
\end{tabular}

slip is critical for ultra-low clearance and/or high-temperature operation bearings where high values of Knudsen number are encountered. Table 3 shows the Knudsen number for various gases at NTP at different film thicknesses. The effect of slip is more pronounced with helium as lubricant followed by nitrogen and argon, which can be directly attributed to the values of Knudsen number at the same operating conditions.

\section{Conclusion}

Slip flow is a prominent phenomenon in gas bearings operating under low and ultra-low clearances. In this paper, a modified aerodynamic model of a GFJB is proposed to assess the influence of slip flow over various performance parameters of the bearing. The model encompasses first-order velocity slip at the solid-gas interface, compliance of the foil, and compressibility of the gas.

The numerical analysis reveals a decline in the generated hydrodynamic pressure and load-carrying capacity on the onset of slip. The conventional Reynolds equation overestimates the peak hydrodynamic pressure and load-carrying capacity by $5.56 \%$ and $8.21 \%$, respectively. The operating eccentricity ratio decreases at the outset of slip flow while an identical minimum film thickness is maintained under no-slip and slip flow conditions. A trivial ascend in the attitude angle is observed for slip flow, indicating a frivolous decline in the stability of the bearing. Thus, for $K n>0.01$, a substantial influence of slip flow on the load-carrying capacity of the GFB is realized and hence, must be considered during the analysis and modeling. The study also shows the effect of slip is enhanced at high speed and by decreasing the gap between the journal and the top foil. 
It should be noted that the present model is valid for $\mathrm{K} n<0.1$. For values of $\mathrm{Kn}>0.1$, the higher-order slip terms can be no longer neglected and it is vital to take cognizance of the second-order slip or 1.5-order slip at the boundary.

\section{Compliance with ethical standards}

Conflict of interest The author(s) declared no potential conflicts of interest with respect to the research, authorship, and/or publication of this article.

\section{Appendix 1}

\section{Modified Reynolds equation formulation}

Considering a control volume of the fluid in the lubricating film, the momentum balance obtained by Navier-Stokes equation yields

$\frac{\partial p}{\partial x}=\mu \frac{\partial^{2} u}{\partial y^{2}}$ and $\frac{\partial p}{\partial z}=\mu \frac{\partial^{2} w}{\partial y^{2}}$

On account of the slip, the modified boundary conditions for the Navier-Stokes equation are

$$
\begin{gathered}
\text { At } y=0, u=U+\left.\beta \frac{\partial u}{\partial y}\right|_{y=0} \quad \text { At } y=h, u=-\left.\beta \frac{\partial u}{\partial y}\right|_{y=h} \\
\text { At } y=0, w=\left.\beta \frac{\partial w}{\partial y}\right|_{y=0} \text { At } y=h, w=-\left.\beta \frac{\partial w}{\partial y}\right|_{y=h}
\end{gathered}
$$

where $\beta=\frac{2-\sigma}{\sigma} \lambda$

Thus, the velocities $u$ and $w$ in $x$ and $z$-direction, respectively, are given as

$$
\begin{aligned}
u & =-\frac{1}{2 \mu}\left(\frac{\partial p}{\partial x}\right)\left\{\beta h+y h-y^{2}\right\}+U\left(1-\frac{y+\beta}{h+2 \beta}\right) \\
w & =-\frac{1}{2 \mu}\left(\frac{\partial p}{\partial z}\right)\left\{\beta h+y h-y^{2}\right\}
\end{aligned}
$$

The continuity equation for compressible fluid, given as

$\frac{\partial}{\partial x}(\rho u)+\frac{\partial}{\partial z}(\rho w)=0$

is combined with velocities from Eq. (10) to yield

$\frac{\partial}{\partial x}\left[\frac{\rho h^{3}}{12 \mu}\left(\frac{\partial p}{\partial x}\right)\left\{1+6 \frac{\beta}{h}\right\}\right]+\frac{\partial}{\partial z}\left[\frac{\rho h^{3}}{12 \mu}\left(\frac{\partial p}{\partial z}\right)\left\{1+6 \frac{\beta}{h}\right\}\right]=\frac{U}{2} \frac{\partial}{\partial x}(\rho h)$

Equation (12) represents the Modified Reynolds equation for slip flow at the solid-fluid interface.

For ideal gas, $\rho=\frac{p}{R_{0} T^{\prime}}$, where $R_{0}$ is the characteristic gas constant. For isothermal condition, equation (12) can be written as,

$$
\begin{aligned}
\frac{\partial}{\partial x} & {\left[p h^{3} \frac{\partial p}{\partial x}\left\{1+6\left(\frac{2-\sigma}{\sigma}\right) K n\right\}\right] } \\
& +\frac{\partial}{\partial z}\left[p h^{3} \frac{\partial p}{\partial z}\left\{1+\sigma\left(\frac{2-\sigma}{\sigma}\right) K n\right\}\right]=6 \mu U \frac{\partial}{\partial x}(p h)
\end{aligned}
$$

Equation (13) is the isothermal Modified Reynolds equation for compressible fluid.

\section{Appendix 2}

\section{Discretization methodology}

Using central-difference scheme of discretization along $\theta$ and $z$-direction and rearranging the terms, LHS and RHS of Eq. 6 can be written as

$$
\begin{aligned}
L H S= & -2 \bar{p}_{i, j}\left[\frac{1}{(\Delta \theta)^{2}}+\left(\frac{D}{L}\right)^{2} \frac{1}{(\Delta \bar{z})^{2}}\right] \\
& +\frac{\bar{p}_{i, j+1}+\bar{p}_{i, j-1}}{(\Delta \theta)^{2}}+\left(\frac{D}{L}\right)^{2} \frac{\bar{p}_{i+1, j}+\bar{p}_{i-1, j}}{(\Delta \bar{z})^{2}}
\end{aligned}
$$

and

$$
\begin{array}{r}
R H S=-\frac{1}{\bar{p}_{i, j}}\left[\left\{\frac{\bar{p}_{i, j+1}-\bar{p}_{i, j-1}}{2 \Delta \theta}\right\}^{2}+\left(\frac{D}{L}\right)^{2}\left\{\frac{\bar{p}_{i+1, j}-\bar{p}_{i-1, j}}{2 \Delta \bar{z}}\right\}^{2}\right]- \\
+\frac{1}{H_{j}}\left(\frac{H_{j+1}-H_{j-1}}{2 \Delta \theta}\right)\left(\frac{\bar{p}_{i, j+1}-\bar{p}_{i, j-1}}{2 \Delta \theta}\right) \\
+\frac{\Lambda}{H_{j} \bar{p}_{i, j}}\left[\bar{p}_{i, j}\left(\frac{\bar{h}_{j+1}-\bar{h}_{j-1}}{2 \Delta \theta}\right)+\bar{h}_{j}\left(\frac{\bar{p}_{i, j+1}-\bar{p}_{i, j-1}}{2 \Delta \theta}\right)\right]
\end{array}
$$


Equating Eqs. (14) and (15) and rearranging the terms, we

get

$\bar{p}_{i, j}=\frac{1}{\kappa}\left[\begin{array}{c}-\frac{1}{\bar{p}_{i, j}}\left[\left\{\frac{\bar{p}_{i, j+1}-\bar{p}_{i, j-1}}{2 \Delta \theta}\right\}^{2}+\left(\frac{D}{L}\right)^{2}\left\{\frac{\bar{p}_{i+1, j}-\bar{p}_{i-1, j}}{2 \Delta \bar{z}}\right\}^{2}\right]-\frac{1}{H_{j}}\left(\frac{H_{j+1}-H_{j-1}}{2 \Delta \theta}\right)\left(\frac{\bar{p}_{i, j+1}-\bar{p}_{i, j-1}}{2 \Delta \theta}\right) \\ +\frac{\Lambda}{H_{j} \bar{p}_{i, j}}\left[\bar{p}_{i, j}\left(\frac{\bar{h}_{j+1}-\bar{h}_{j-1}}{2 \Delta \theta}\right)+\bar{h}_{j}\left(\frac{\bar{p}_{i, j+1}-\bar{p}_{i, j-1}}{2 \Delta \theta}\right)\right]-\frac{\bar{p}_{i, j+1}+\bar{p}_{i, j-1}}{(\Delta \theta)^{2}}+\left(\frac{D}{L}\right)^{2} \frac{\bar{p}_{i+1, j}+\bar{p}_{i-1, j}}{(\Delta \bar{z})^{2}}\end{array}\right]$

where,

$\kappa=-\left[\frac{2}{(\Delta \theta)^{2}}+\left(\frac{D}{L}\right)^{2} \frac{2}{(\Delta \bar{z})^{2}}\right]$

\section{References}

1. Sim K, Lee YB, Kim TH (2013) Effects of mechanical preload and bearing clearance on rotordynamic performance of lobed gas foil bearings for oil-free turbochargers. Tribol Trans 56(2):224235. https://doi.org/10.1080/10402004.2012.737502

2. Lucero JM, DellaCorte C (2004) Oil-free rotor support technologies for long life, closed cycle brayton turbines. In: Collection of technical papers-2nd international energy conversion engineering conference, vol 3, pp 1583-1591. https://doi. org/10.2514/6.2004-5720

3. Belforte G, Colombo F, Raparelli T, Trivella A, Viktorov V (2013) High speed rotors on gas bearings: design and experimental characterization. In: Tribology in engineering. InTech

4. Waumans T, Peirs J, Al-Bender F, Reynaerts D (2011) Aerodynamic journal bearing with a flexible, damped support operating at 72 million DN. J Micromech Microeng. https://doi. org/10.1088/0960-1317/21/10/104014

5. Heshmat $\mathrm{H}$ (1994) Advancements in the performance of aerodynamic foil journal bearings: high speed and load capability. J Tribol 116(2):287-294. https://doi.org/10.1115/1.2927211

6. Heshmat H, Walowit JA, Pinkus O (1983) Analysis of gas-lubricated foil journal bearings. J Tribol 105(4):647-655. https://doi. org/10.1115/1.3254697

7. Peng JP, Carpino M (1993) Calculation of stiffness and damping coefficients for elastically supported gas foil bearings. J Tribol 115(1):20-27. https://doi.org/10.1115/1.2920982

8. Peng J-P, Carpino M (1994) Coulomb friction damping effects in elastically supported gas foil bearings $\odot$. Tribol Trans 37(1):9198. https://doi.org/10.1080/10402009408983270

9. Dellacorte C, Valco MJ (2000) Load capacity estimation of foil air journal bearings for oil-free turbomachinery applications. Tribol Trans 43(4):795-801. https://doi.org/10.1080/104020000089824 10

10. Peng ZC, Khonsari MM (2004) Hydrodynamic analysis of compliant foil bearings with compressible air flow. J Tribol 126(3):542546. https://doi.org/10.1115/1.1739242

11. Faria MTC, San Andrés L (2000) On the numerical modeling of high-speed hydrodynamic gas bearings. J Tribol 122(1):124-130. https://doi.org/10.1115/1.555335

12. Rubio D, San Andrés L (2006) Bump-type foil bearing structural stiffness: experiments and predictions. J Eng Gas Turbines Power 128(3):653-660. https://doi.org/10.1115/1.2056047

13. Lee YB, Park DJ, Kim CH, Kim SJ (2008) Operating characteristics of the bump foil journal bearings with top foil bending phenomenon and correlation among bump foils. Tribol Int 41(4):221-233. https://doi.org/10.1016/j.triboint.2007.07.003

14. Samanta P, Murmu NC, Khonsari MM (2019) The evolution of foil bearing technology. Tribol Int 135(March):305-323. https://doi. org/10.1016/j.triboint.2019.03.021

15. Hou Y, Chen S, Chen R, Zhang Q, Zhao H (2011) Numerical study on foil journal bearings with protuberant foil structure. Tribol Int 44(9):1061-1070. https://doi.org/10.1016/j.triboint.2011.04.015

16. Feng K, Zhao X, Huo C, Zhang Z (2016) Analysis of novel hybrid bump-metal mesh foil bearings. Tribol Int 103:529-539. https:// doi.org/10.1016/j.triboint.2016.08.008

17. Cable TA, San Andrés L (2018) On the design, manufacture, and premature failure of a metal mesh foil thrust bearing - how concepts that work on paper, actually do not. J Eng Gas Turbines Power 140(12):1. https://doi.org/10.1115/1.4041137

18. Lai T, Guo Y, Zhao Q, Wang Y, Zhang X, Hou Y (2018) Numerical and experimental studies on stability of cryogenic turboexpander with protuberant foil gas bearings. Cryogenics (Guildf) 96:62-74. https://doi.org/10.1016/j.cryogenics.2018.10.009

19. Tkacz E, Kozanecki Z, Kozanecka D, Łagodziński J (2017) A self-acting gas journal bearing with a flexibly supported foilnumerical model of bearing dynamics. Int J Struct Stab Dyn 17(5):1-11. https://doi.org/10.1142/S0219455417400120

20. Hou Y, Ma B, Yang S, Chen X, Zheng Y, Chen S (2015) Experimental study on bump-foil gas bearing with different diametric clearance configurations. J Mech Sci Technol 29(5):2089-2095. https://doi.org/10.1007/s12206-015-0430-5

21. Li Y, Lei G, Sun Y, Wang L (2017) Effect of environmental pressure enhanced by a booster on the load capacity of the aerodynamic gas bearing of a turbo expander. Tribol Int 105:77-84. https:// doi.org/10.1016/j.triboint.2016.09.027

22. Kayo C, Liebich R (2019) Experimental structural analysis of gas foil bearings. In: Mechanisms and machine science, vol 60 . Springer, Netherlands, pp 264-280

23. Branagan M, Griffin D, Goyne C, Untaroiu A (2016) Compliant gas foil bearings and analysis tools. J Eng Gas Turbines Power 138:1-8. https://doi.org/10.1115/1.4031628

24. Burgdorfer $A$ (1959) The influence of the molecular mean free path on spherical thrust gas bearing performance. ASME J Basic Eng 81(2):94-100. https://doi.org/10.1016/0043-1648(79)90118 $-2$

25. Hsia YT, Domoto GA (1983) An experimental investigation of molecular rarefaction effects in gas lubricated bearings at ultra-low clearances. J Tribol 105(1):120-129. https://doi. org/10.1115/1.3254526

26. Hirani $H$ (2016) Fundamentals of engineering tribology with applications. Cambridge University Press, Cambridge

27. Chapman S, Cowling TG (1990) The mathematical theory of nonuniform gases: an account of the kinetic theory of viscosity, thermal conduction and diffusion in gases. Cambridge University Press, Cambridge 
28. S. Colin (2006) Single-Phase Gas Flow in Microchannels. In: Heat transfer and fluid flow in minichannels and microchannels. Elsevier Ltd, pp 9-86

29. Colin S, Lalonde P, Caen R (2004) Validation of a second-order slip flow model in rectangular microchannels. Heat Transf Eng 25(3):23-30. https://doi.org/10.1080/01457630490280047

30. Khonsari MM, Booser ER (2017) Applied tribology: bearing design and lubrication. Wiley, Chichester
31. Zhou W, Wei X, Wang L, Wu G (2017) A superlinear iteration method for calculation of finite length journal bearing's static equilibrium position. R Soc Open Sci 4(5):1. https://doi. org/10.1098/rsos.161059

Publisher's Note Springer Nature remains neutral with regard to jurisdictional claims in published maps and institutional affiliations. 